\title{
Research on Temperal-spatial Characteristics of Microseismic Activity in Hard Rock Tunnel at Baihetan Hydropower Station
}

\author{
Huaji Liu ${ }^{a}$, Bingrui Chen ${ }^{b}$, Yaxun Xiaoc \\ State Key Laboratory of Geomechanics and Geotechnical Engineering, Institute of Rock and Soil \\ Mechanics, Chinese Academy of Sciences, Wuhan, Hubei 430071, China \\ aliuhuaji2010@163.com, bbrchen@whrsm.ac.cn, cxyxrock@gmail.com
}

Keywords: underground cavern; microseismic monitoring; underground water; excavation rate; structural plane

Abstract. The underground cavern group of Baihetan hydropower station is characteristic with complex geological condition, large buried depth and high stress, the local failures of surrounding rock mass which often occurred frequently during the construction process. To study the mechanisms of failures result from the unloading effect of excavation, in situ microseismic monitoring system was established on the No.1 construction branch tunnel of spillway tunnel located on the left bank of Baihetan Hydropower Station, the relation between microseismic activity, geological condition and failures of surrounding rock is studied. The results show that: 1) the region with abundant underground water was hard to gather stress and energy quickly in short time. 2) a low excavation rate weakened the risk of the failure of the surrounding rock of hard rock tunnel because of the unload effect of excavation. 3) the microseismic events were more active on north side of the tunnel and assembled on the north spandrel with opening structure plane.4) the risk of rockburst in the microseismic monitoring tunnel during the excavation is low. The research results provide reference for the optimization of the excavation and support and are meaningful for reducing the risk of the rock failures during the excavation.

\section{Introduction}

Baihetan Hydropower Station is located in the second stage of the four hydropower stations on the downstream of the Jinsha river, which is a huge hydropower engineering and second only to the Three Gorges Hydropower Station in China. The regional geological condition of the underground cavern group at Baihetan is complicated. The maximal principal stress of underground powerhouse on left bank and right bank is about $23 \mathrm{MPa}$ and $26 \mathrm{MPa}$ respectively. Under the condition of high stress, there's a higher risk of spalling, rockburst and stress-controlled collapse during the construction of tunnels. For instance, in October 18, 2013, a moderate rockburst occurred on left vault at the position of K0+285 in No.1 construction branch tunnel of spillway tunnel on the downstream left bank of Baihetan Hydropower station, which make drilling workers injured. In order to ensure the workers' personnel safety and continuous excavation, in October 20, 2013, the ISS microseismic (MS) monitoring system was established to monitor the surrounding rock mass failure timely in the tunnel and give warning of the rockburst risk.

Microseismic is a new engineering safety monitoring technology, which can obtain the time, location, energy and other information about the surrounding rock mass fracture in advance by using the sensors and location arithmetic. With the significant advantages, microseismic monitoring technique has been widely used in many projects and achieved remarkable achievements, such as deep mines, tunnels, slope and underground laboratory at South Africa, Canada, the United States and China [1-7]. Jianpo Liu et al. [8] established microseismic monitoring system in Hongtou Mountain Copper Mine to study the relationship between microseismic activities and mining. The potential danger zone of rock mass failure was estimated by the monitoring data. Biao Li et al. [9] used the microseismic monitoring information about the Houziyan Hydropower Station underground powerhouse to recognize and estimate the damaged zone of the tunnels under the unload effect of excavation. Xiating Feng et al. [10] studied the time and space evolution law of immediate rockburst according to the microseismic monitoring information at the Jinping II Hydropower Station. 
Therefore, microseismic has been verified to be an effective monitoring technology to prevent the high-risk damaged zone of rock mass under the high stress.

Based on the engineering of No.1 construction branch tunnel of spillway tunnel on left bank of Baihetan Hydropower station, the microseismic monitoring system was established in the tunnel to give early warning of the rockburst. The time and space evolution law of microseismic activity during the excavation process was studied and the stability of the tunnel after excavation was analyzed by combining monitoring information, geologic condition and construction situation. This paper can provides guiding for construction in situ and supports for studying the stability of underground cavern under the similar condition.

\section{Geologic Condition of the Tunnel}

The excavation method of No.1 construction branch tunnel of spillway tunnel was drilling and blasting. To study the dynamic connection of geologic condition and surrounding rock mass fracture during the excavation, an on-the-spot survey was conducted in the tunnel. The geological condition changed with the mileage of the tunnel was shown in Fig.1.

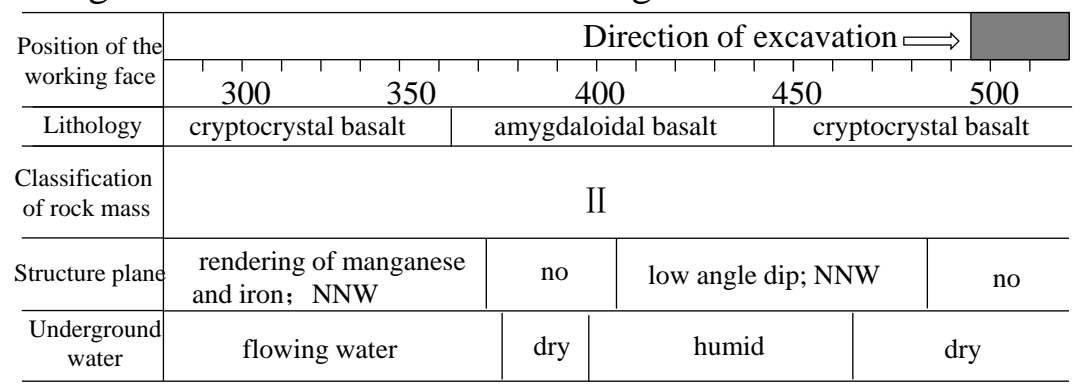

Fig.1 Recording diagram of geologic investigation

In total, the regional geological condition of the monitoring tunnel was complicated. There's a large group of structural planes with orientation of NNW in this tunnel and the interval between the structural planes was about $20 \mathrm{~cm} \sim 30 \mathrm{~cm}$. The surface of structural planes was in the rendering of manganese and iron. There's no preponderant structural plane exposed in local zone. The underground water in the tunnel was active and the environment was humid. The surrounding rock mass classification of the monitoring tunnel was II. The lithology of the tunnel was mostly cryptocrystal basalt and local region was amygdaloidal basalt. The intensity of the basalt was hard.

\section{Layout of Sensors}

Considering the construction and monitoring condition of the No.1 construction branch tunnel of spillway tunnel, the highly sensitive geophone sensors were selected for this monitoring plan. As shown in Fig.2, MS1-2, MS2-1, MS2-4 and MS3-2 were triaxial wave recording types and the others were uniaxial types. The scheme of microseismic sensors was designed for capturing the signals of rock fracturing. The sensors were arranged on three cross sections and the interval of two sections was $15 \mathrm{~m}$. The first row of sensors was $50 \mathrm{~m}$ away from the working face, and when the working face moved forward $15 \mathrm{~m}$, the last row of sensors rearranged on the position $50 \mathrm{~m}$ away from the working face. The sensors changed with the working face moving forward and the distance between sensors and the working face was less than $100 \mathrm{~m}$. Retrievable device was used for installing the sensors into the boreholes. 


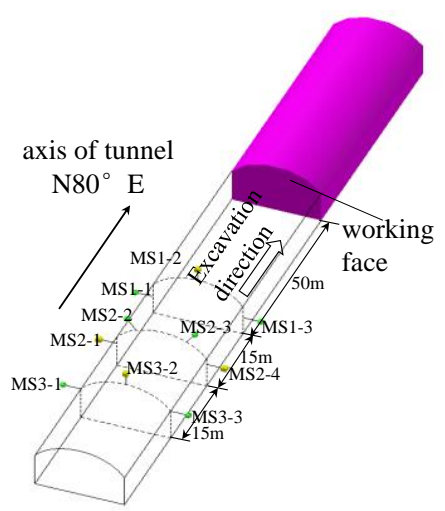

(a) stereogram of distribution of sensors

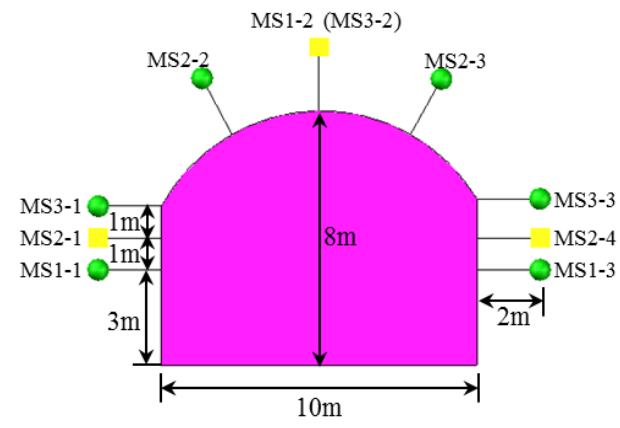

(b) section view of distribution of sensors

Fig.2 Spatial distribution of microseismic sensors

\section{Temporal Distribution Characteristics of Microseismic Events}

The microseismic monitoring system was operating from October 26, 2013 to December 5, 2013. Considering the timeliness of the rock fracturing, the microseismic monitoring system continued working up to December 11, 2013 to study development tendency of the stability of the surrounding rock mass. There're 168 effective microseismic events captured after analyzing and filtering the noise signals. In general, the microseismic activity analysis zone ranged from $30 \mathrm{~m}$ behind working face to $20 \mathrm{~m}$ ahead [11]. As is shown in Figs 3, the number of microseismic events fluctuated up and down with the change of time. Overall, the microseismic activity was weak, and the frequency of rock fracture was low. There're 77 effective microseismic events in total in the analysis zone. Maximum of the events' number is 88 , minimum of the number is 0 and the average of number is 2.2 every day. Fig 4 shows the evolution law of the strength of microseismic activity. The magnitude of the microseismic events ranged from -5.8 to -1.6 . Most microseismic events' magnitude was less than -3 , and occupied the proportion of $79 \%$. The microseismic events with relatively high magnitude were scattered and didn't gathered in a period of time. The monitoring results showed the microseismic activities of surrounding rock mass were relatively flat and there's no rapid accumulation of micro-fracture result from the excavation.

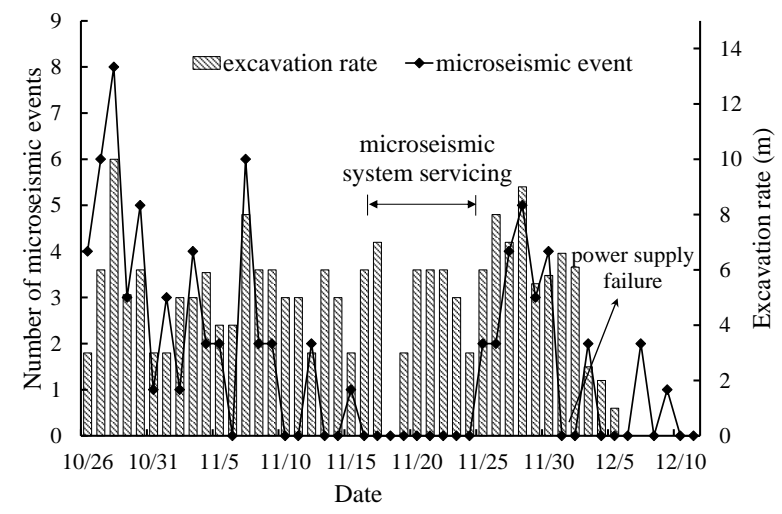

Fig.3 Evolution of numbers of microseismic events 


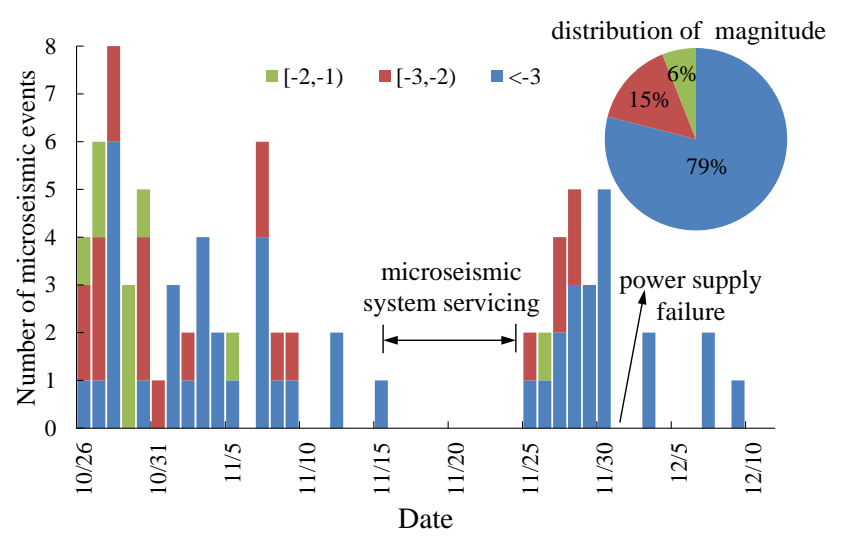

Fig.4 Magnitude distribution of microseismic events

Combined with the geologic condition and underground water activity, it is easy to find that the water flowing fractures existed in the tunnel extensively. Water softened the structure face and reduced the strength of rock mass, which caused the strain energy was hard to rapidly accumulate in the analysis zone. The risk of rockburst is low, but it still should pay attention to the risk of collapse in local regions. This studying result of this paper is consistent with the research of Runqiu Huang [12].

In addition, it also can be seen from Fig.3 that the excavation rate had a great influence on the microseismic activity. With the exception of reasons leading to the monitoring of the suspension, the evolution trend of microseismic activity was consistent with the trend of excavation rate. For example, in the October 28, November 7 and November 28, the excavation rate was relatively fast and daily excavation rate was more than $8 \mathrm{~m}$. In this period of time, the microseismic activities were more frequent and the strengths of them were relatively high. However, when the excavation rate was about $4 \mathrm{~m}$ per day, the microseismic activity frequency was obviously low. After the completion of excavation of the tunnel, there're only three effective microseismic events occurred within five days. The number of microseismic events gradually decreased, and the microseismic activity tends to be calm.

It is generally believed that the correlation between microseismic activity and excavation rate was affected by the stress distribution of excavation disturbance. The stress adjustment and redistribution of the surrounding rock caused by the unloading effect of the excavation of the tunnel lead to the stress concentration and energy accumulation in the local area. When the stress reached to a certain extent, the surrounding rock mass began to fracture and release energy. If the tunnel excavation rate is too fast, the stress sharply changed and a large number of micro-crack initiated in the surrounding rock mass. Therefore, it is suggested that when the number of microseismic events became large, the tunnel excavation rate should be controlled at about $4 \mathrm{~m}$ per day to reduce the risk of rock damage caused by excavation unloading effect.

\section{Spatial Distribution Characteristics of Microseismic Events}

Fig. 5 shows the spatial distribution of the microseismic events during the excavation period. The spheres represent the microseismic events in the spatial distribution. The size of the sphere represents the energy released by the event. The larger the size, the more energy is released. The color of sphere represents the magnitude of the fractures, which is shown in the legend. Fig. 5(a) shows that the microseismic events are distributed around the excavated tunnel in the space, and there is no obvious spatial aggregation phenomenon. There're only a few events with relatively large energy is scattered in the local area. It can also be found that the microseismic activity of the left bank (north) of the tunnel is more active than that of the right (south) bank. As is shown in Fig. 5(b), the microseismic events is relatively concentrated at the position of K0+330 on the left spandrel of the tunnel, and when the working face reached here, the rock chipped. An opening structure plane was found at this position through geographical investigating, which is easy to be rock failure under the loading effect of excavation. The microstructural monitoring results are consistent with the damage of the 
surrounding rock in the field. At the same time, the construction suggestions are recommended to the construction teams in time to prevent the loss.

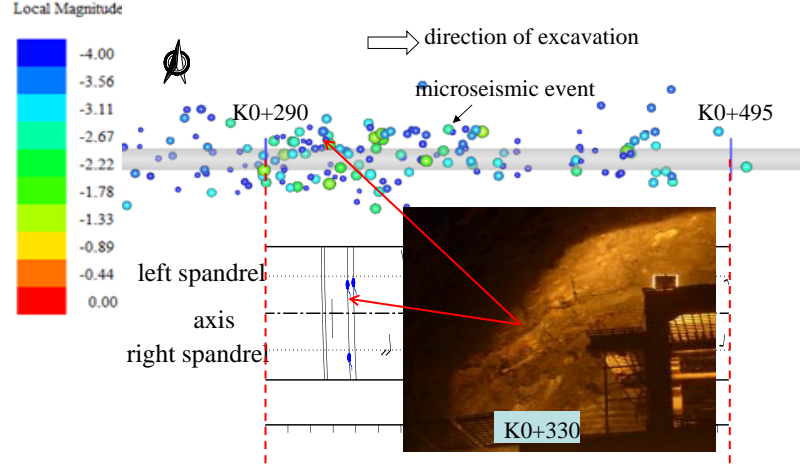

(a) distribution of microseimic events along the axis microseismic events around $\mathrm{K} 0+330$

\section{Fig.5 Spatial distribution of microseismic events}

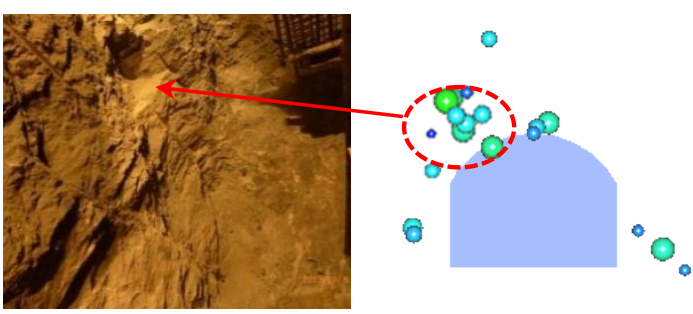

(b) section view of distribution of

\section{Risk Analysis of Rockburst}

According to the geological conditions exposed during the excavation process, the lithology of the microseismic monitoring tunnel is mainly basalt and its uniaxial compressive strength is about 130 $150 \mathrm{MPa}[13]$. In the feasibility study stage, the maximum stress in this tunnel was about $22 \mathrm{MPa}$, which is estimated by the design institute. The ratio of intensity to stress $\left(\sigma_{c} / \sigma_{1}\right)$ is about $5.9 \sim 6.8$. Based on the criteria of GB50218-94, rockburst, spalling and collapsing may occur in this tunnel [14].

The rockburst risk analysis often uses the micorseismic monitoring information, such as the apparent volume and energy index. The sudden increase of the apparent volume and the sudden decrease of the energy index means that the rock mass may be unstable [15]. The apparent volume is expresses inelastic deformation volume of rock mass in the source, which can be symbolized by VA. The energy index is the ratio of released energy by a microseismic event to the average microseismic energy of all events in the region, which can be symbolized by EI. As is shown in Fig. 6, the apparent volume gradually increased during the excavation process and the energy index curve fluctuated up and down. But there's no period time when a significant increase of the apparent volume and sudden drop of the energy index at the same time. It indicates that there's no obvious characteristic of the rockburst and instability of the rock mass during the excavation. All in all, the risk of rockburst of the monitoring tunnel is low during the excavation process.

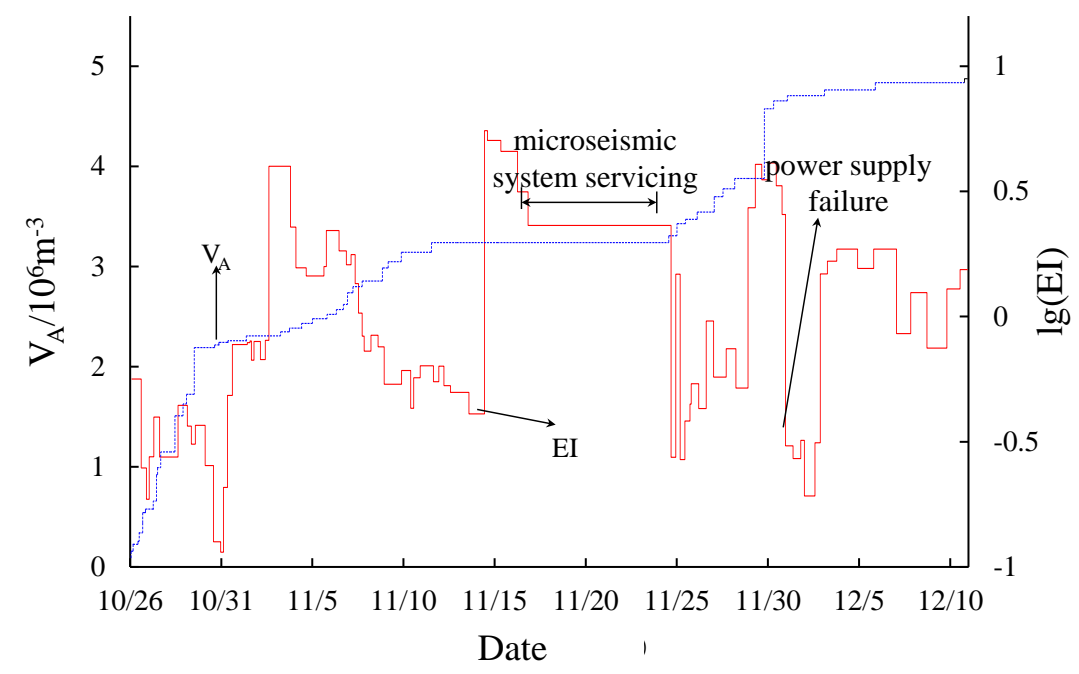

Fig.6 Evolution laws of apparent volume and energy index 


\section{Conclusions}

The evolution law and development trend of microseismic activities during the construction of No.1 construction branch tunnel of spillway tunnel were monitored by the application of microseismic monitoring technology. Besides, to analyze the characteristic of the surrounding rock fracture and the relationship between microseismic activities and rock fracture, the geological conditions changed with the movement of the working face was investigated. The risk of rockburst was also analyzed based on the monitoring information. The main conclusions are summarized as follows:

(1) The microseismic activity of the surrounding rock is related to the groundwater activity of the tunnel. The existence of the water flowing fractures in the monitoring tunnel leads to the lack of condition of storing energy during the excavation of the hard rock tunnel. The energy is not easy to gather and rockburst usually won't occur in this region. But it is possible to collapse in local regions, which need to be taken care of.

(2) The microseismic activity of the surrounding rock of the hard rock tunnel is affected by the excavation rate significantly. Reducing the excavation rate can effectively decrease the frequency of microseismic activity and weaken the influence of excavation unloading on the surrounding rock of hard rock tunnel. In the case of regions of the hard rock tunnel with higher risk of damage, the frequency of microseismic activity can be weakened by reducing the excavation rate.

(3) The microseismic events are more easy to gather on the left (north) spandrel of the hard rock tunnel, where the surrounding rock mass is more likely to be damaged. Therefore, the risk of rock failure is relatively high on the left arch of the tunnel and supporting measures should be adopted in these regions timely.

(4) There is no obvious increase of the apparent volume and sudden drop of the energy index during the excavation of the tunnel, so the risk of rockburst is low.

The characteristics of the surrounding rock fracturing are analyzed comprehensively in this paper. The relationship between the microseismic activity, geological condition, and rock fractures is studied. Some preliminary conclusions are summarized. The in situ microseismic monitoring data includes other important information, such as moment tensor and wave spectrum, which are of great significance to explore the characteristics and mechanism of surrounding rock fractures in hard rock tunnel. The scheme of excavation and support measures can also be optimized by the analysis results of the monitoring information. For example, the types of the surrounding rock fractures can be divided by the moment tensor analysis, which provides the basis for the selection of support measures and will be the focus of the following study.

\section{Acknowledgements}

This work is financially supported by the National Natural Science Foundation of China under Grant nos. 51539002 and 51509244. The assistance for the in situ microseismic monitoring from Professors Shaojun Li, Dr. Guangliang Feng, Zhibin Yao is acknowledged.

\section{References}

[1] Cai, M., Kaiser, P., \& Martin, C. International Journal of Rock Mechanics and Mining Sciences, 2001, 38(8):1135-1145

[2] Maochen Ge. International Journal of Coal Geology, 2005, 64(1):44-56

[3] Anye Cao, Linming Dou, Yuhong Qin, Zhihua Li. Coal Ming Technology. 2007,12(1), 20-23. (in Chinese)

[4] Yaxun Xiao, Xiating Feng, Hudson, J. A., et al. Rock Mechanics and Rock Engineering, 2016, 49(1):343-369

[5] Fuxing Jiang, Genxi Ye, Cunwen Wang, et al. Chinese Journal of Rock Mechanics and Engineering, 2008, 27(9), 1932-1938.(in Chinese) 
[6] Lizhong Tang, Jun Zhang, Xibing Li, et al. Chinese Journal of Rock Mechanics and Engineering, 2012, 31(7), 1349-1354.(in Chinese)

[7] Mendecki,A.J. Seismic monitoring in mines[M].Springer Science \& Business Media., $1997,: 220-245$

[8] Jianpo Liu, Changyan Shi, Yuanhui Li, et al. Journal of Mining \& safety engineering. 2012, 29(1):72-77.(in Chinese)

[9] Biao Li,Feng Dai,Nuwen Xu,et al. Chinese Journal of Rock Mechanics and Engineering, 2014, 33(3): 375-3. (in Chinese)

[10]Xiating Feng, Bingrui Chen, Huajun Ming, et al. Chinese Journal of Rock Mechanics and Engineering, 2012, 31(03):433-444. (in Chinese)

[11]Zhouneng Zhao, Xiating Feng, Bingrui Chen, et al. Rock and Soil Mechanics,2013,34(2):491-497.(in Chinese)

[12]Runqiu Huang, Xianneng Wang, Tang Sheng-chuan, et al.Journal of geological hazards and environment preservation, 1997, 08(01):51-69. (in Chinese)

[13] Guofeng Liu, Xiating Feng, Quan Jiang, et al. Chinese Journal of Rock Mechanics and Engineering, 2016,35(05):865-878..(in Chinese)

[14]The National Standard Compilation Group of People's Republic of China. 50218-94., The Standard for Engineering Classification of Rock Mass [S]. Beijing: China Planning Press,2002.(in Chinese)

[15]Bingrui Chen, Xiating Feng, Xionghui Zeng, et al. Chinese Journal of Rock Mechanics and Engineering,2011,30(2):275-283.(in Chinese) 